\title{
Fístula uretral em cão
}

\author{
Urethral fistula in dog \\ Liziane Ferraresi Holanda Cavalcante', Daniel Menezes da Rosa', Emerson \\ Antonio Contesini², Alan Gomes Pöppl ${ }^{3}$, Rafael Stedile ${ }^{4}$ \& Gabriela Sessegolo ${ }^{5}$
}

\begin{abstract}
RESUMO
As fístulas uretrais são de ocorrência rara dentre as uretropatias caninas e podem, às vezes, serem confundidas com uretra dupla ou hipospadias. O presente relato descreve o caso de um cão, sem raça definida (SRD), 1 ano de idade, atendido no Hospital de Clínicas Veterinárias da Universidade Federal do Rio Grande do Sul (HCV-UFRGS) com histórico de agitação e relutância em caminhar. Ao exame físico, o animal apresentava sinais sugestivos de intoxicação, associado à ingestão de deltametrina. Ainda na consulta, o proprietário referiu-se a um orifício pelo qual o animal urinava, próximo ao ânus, mas que urinava também pelo pênis. Recuperado do quadro de intoxicação, o animal foi submetido a exames de triagem como: hemograma completo, urinálise com antibiograma e uretrocistografia com contraste positivo, utilizando Iodamida de meglumina. Estes revelaram cistite acentuada, urina positiva para Escherichia coli, e também a presença de fístula uretral perianal. Encaminhado para cirurgia, realizou-se dissecção do trajeto fistuloso, com posterior síntese plano a plano utilizando-se poliglactina 910 no subcutâneo e náilon-poliamida na pele. $\mathrm{O}$ animal apresentou deiscência dos pontos externos, optando-se por cicatrização por segunda intenção. O trajeto fistuloso dissecado foi encaminhado para exame histopatológico, obtendo-se como resultado a presença de tecido conjuntivo bem diferenciado, compatível com fístula uretral. Após 15 dias realizou-se nova uretrocistografia evidenciando completa remissão do trajeto fistuloso e uretra íntegra, obtendo-se assim, excelente resultado cirúrgico.
\end{abstract}

Descritores: fístula uretral, uretra, cão.

\section{ABSTRACT}

Urethral fistulas are rare of occurrence among canine urethral diseases and can, sometimes, be confused with double urethra or hypospadias. The present story describes a case of a dog, mixed Breed, 1 year old, taken care in the Hospital de Clínicas Veterinárias (HCV), Universidade Federal do Rio Grande do Sul (UFRGS) with history of agitation and reluctance in walking. At physical examination, the animal presented suggestive signs of intoxication, associated to deltametrin ingestion. Still in consultation, the owner mentioned an orifice, through animal was urinating, next to the anus, but he was urinating also through the penis. Recouvered of the poisoning, the animal was submitted to selection examinations such as: complete blood count, urinalysis with antibiogram and cystourethrography with positive constrast, with Iodamida of meglumina. These examinations had disclosed marked cystitis, positive urine for Escherichia coli and presence of urethral perineal fistula. Leading for surgery, the dissection of fistulous tract was fulfilled realized, with posterior synthesis plane to plane, using poliglactina 910 in subcutaneous and nylon in the skin. The animal presented dehiscence of the external points, opting itself to second intention healing. The dissected fistulous tract was sent for histopathological examination, getting itself as resulted, a well differentiated connective tissue, consistent with urethral fistula. After 15 days, a new cystourethrography was realized, evidencing complete remission of the fistulous tract and intact urethra, getting itself thus, excellent surgical result.

Key words: urethral fistula, urethra, dog. 


\section{INTRODUÇÃO}

As anomalias urogenitais são incomuns no cão [11]. As fístulas uretrais podem ser adquiridas, mas comumente são defeitos congênitos. De ocorrência rara, a fistula uretral congênita é uma anomalia controlável que pode ser confundida com hipospadia e/ou duplicação da uretra [4,5,7-9].

Em cães, as fístulas uretrorretais são mais comuns e os Buldogues Ingleses parecem ter predisposição hereditária, sendo capazes de ter micção normal, mas freqüentemente geram um jato adicional de urina pela fístula, através do ânus [4].

Em humanos, a fístula uretral congênita é extremamente rara, com menos de 20 casos relatados, e está associada à má formação anorretais e/ou anormalidades no pênis, sendo que a fistula uretroperineal é a variante mais comum da duplicação uretral $[1,4,7,8,10]$. Já a fístula uretrocutânea adquirida é a complicação mais comum associada a uretroplastia no reparo das hipospadias [2].

A etiologia da fístula uretral congênita ainda não está bem esclarecida, mas várias hipóteses etiológicas têm sido propostas, como: deficiência local/segmentar da camada uretral durante a formação da uretra peniana, a qual evita a fusão das camadas uretrais; aumento da pressão proximal uretral e deficiência local do corpo esponjoso do pênis devido à lesão obstrutiva do meato $[4,8]$. Já as fístulas uretroanais podem ser explicadas pela persistência do ducto cloacal durante a divisão da cloaca, devido à semelhança com os canais perineais descritos em fêmeas com fístulas anorretais [7].

O objetivo deste trabalho é relatar um caso raro de fístula uretral, possivelmente de origem congênita, corrigida cirurgicamente em um cão.

\section{RELATO DE CASO}

Um cão, SRD, macho, 1 ano de idade, pesando $9 \mathrm{~kg}$, foi atendido no HCV-UFRGS com histórico de agitação, relutância em caminhar e sinais de intoxicação (temperatura retal de $35,1^{\circ} \mathrm{C}$, midríase, reflexo pupilar diminuído, desorientação) devido à ingestão de deltametrina $\left(\text { BUTOX }^{\circledR}\right)^{1}$.

No momento da consulta, o proprietário relatou a presença de um orifício pelo qual o animal urinava, próximo ao ânus, entretanto urinava normalmente pelo pênis (Figuras 1 e 2).

Recuperado da intoxicação, o animal foi submetido a exames de triagem tais como: hemograma completo, urinálise e antibiograma e uretrocistografia com contraste positivo, utilizando iodamida de meglumina (UROMIRON $\left.{ }^{\circledR}\right)^{2}$.

O hemograma não apresentou qualquer alteração digna de nota. A urinálise evidenciou cistite acentuada, com a presença de Escherichia coli na urina, sensível a cefalexina, nitrofurantoína e amoxicilina com ácido clavulânico. A uretrocistografia retrógrada com contraste positivo confirmou a presença de fístula uretral perianal (Figura 3).

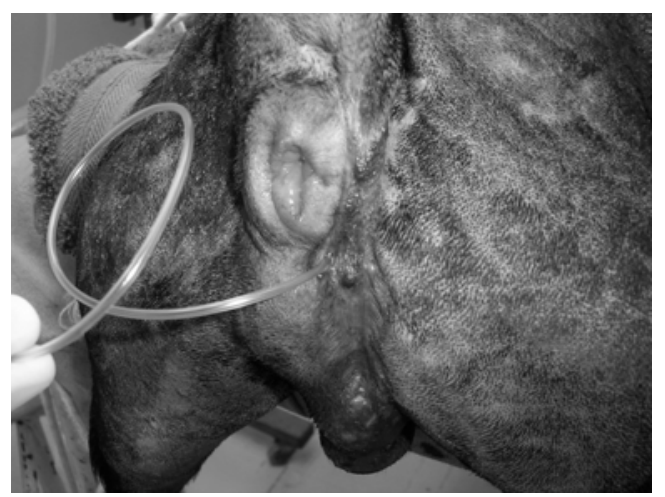

Figura 1. Cão apresentando fístula uretral perianal identificada pela sonda uretral (Liziane Ferraresi Holanda Cavalcante).

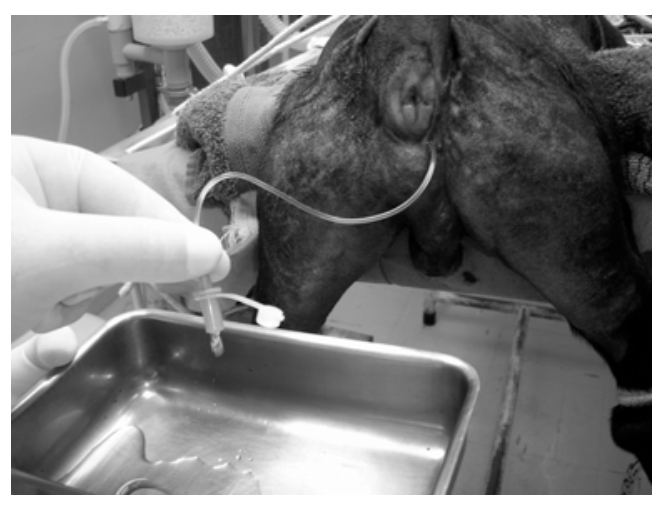

Figura 2. Fluxo urinário originado a partir da fístula (Liziane Ferraresi Holanda Cavalcante).

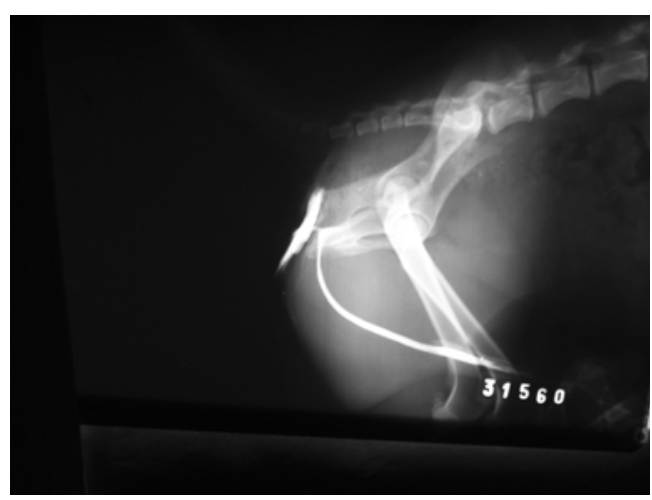

Figura 3. Uretrocistrografia de contraste positivo evidenciando a presença de trajeto fistuloso (setas) (Liziane Ferraresi Holanda Cavalcante). 
O animal, então encaminhado para cirurgia, foi submetido ao seguinte protocolo anestésico - medicação pré-anestésica utilizando acepromazina $0,1 \mathrm{mg} / \mathrm{kg}$, meperidina $3 \mathrm{mg} / \mathrm{kg}$ e ampicilina $22 \mathrm{mg} / \mathrm{kg}$, indução anestésica com propofol $5 \mathrm{mg} / \mathrm{kg}$, bloqueio epidural com lidocaína na dose de $3 \mathrm{mg} / \mathrm{kg}$ e manutenção anestésica com halotano.

O procedimento cirúrgico constou na dissecção do trajeto fistuloso, de tamanho aproximadamente de $2 \mathrm{~cm}$, e retirada do mesmo, aplicando-se ligadura dupla no ponto de junção com a uretra. Posteriormente realizou-se síntese plano a plano utilizando-se fio de poliglactina 910 no subcutâneo e com fio mononylon 2-0 (Figuras 4a e 4b).

O material removido foi encaminhado para o exame histopatológico, no qual foi observada a presença de tecido conjuntivo diferenciado, compatível com fístula uretral (Figura 5a e 5b).

O pós-operatório constou de cefalexina $(300 \mathrm{mg} / \mathrm{kg}$ a cada 12 horas) e nitrofurantoína ( $4 \mathrm{mg} / \mathrm{dia}$ a cada 6 horas), cetoprofeno $(1 \mathrm{mg} / \mathrm{kg}$ a cada 24 horas) por 3 dias e cloridrato de tramadol $(3 \mathrm{mg} / \mathrm{kg}$ a cada 8 horas) por 2 dias, além de curativos diários na região da sutura com solução fisiológica. O animal apresentou deiscência dos pontos cutâneos no quarto dia de pós-operatório, optando-se pela cicatrização por segunda intenção, com o uso de pomada de fibrinolisina, desoxirribonu- clease e cloranfenicol (FIBRASE $\left.{ }^{\circledR}\right)^{3}$. O mesmo foi mantido hospitalizado durante 15 dias para realização de curativos da ferida cirúrgica.

Após 15 dias realizou-se nova uretrocistografia retrógrada com contraste positivo, evidenciando completa remissão do trajeto fistuloso e uretra íntegra (Figura 6).
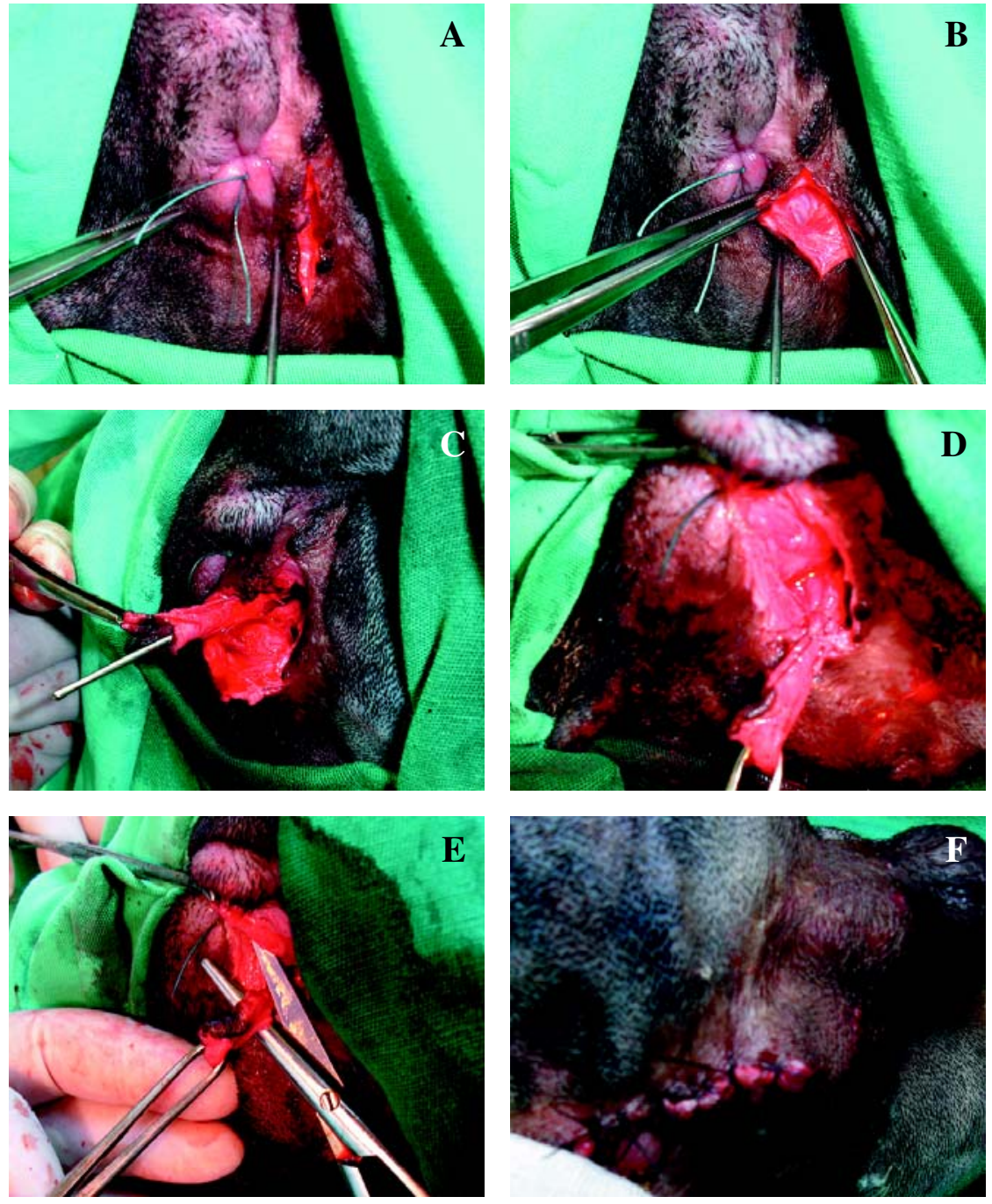

Figura 4 (a, b, c, d, e, f). Dissecção do trajeto fistuloso durante o procedimento cirúrgico e retirada do mesmo (Liziane Ferraresi Holanda Cavalcante).
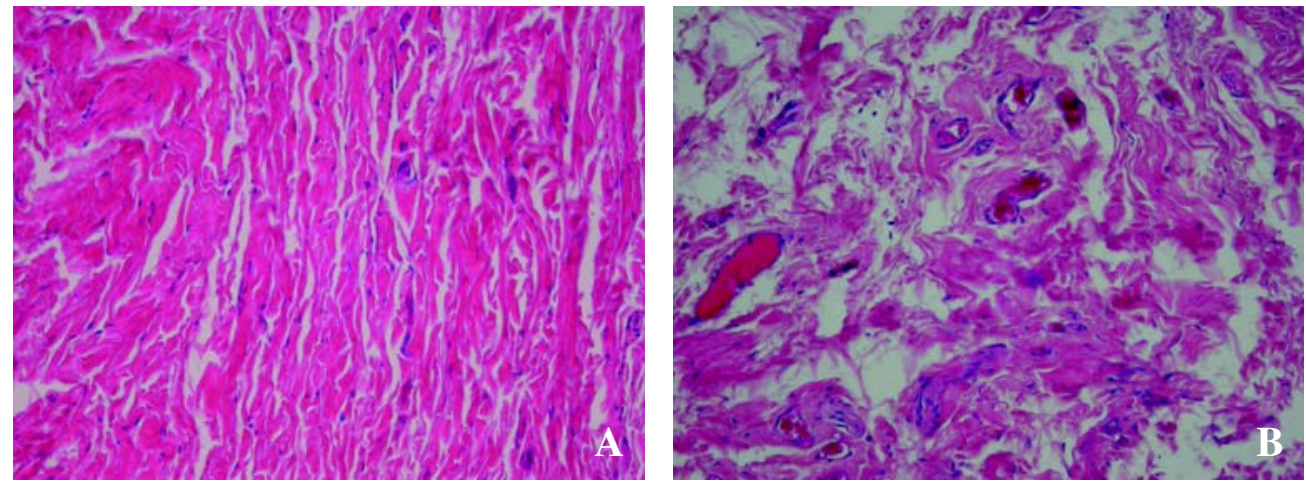

Figura 5 (a e b). Cortes histológicos do trajeto fistuloso demonstrando a presença de tecido conjuntivo (Djeison Raymundo). 


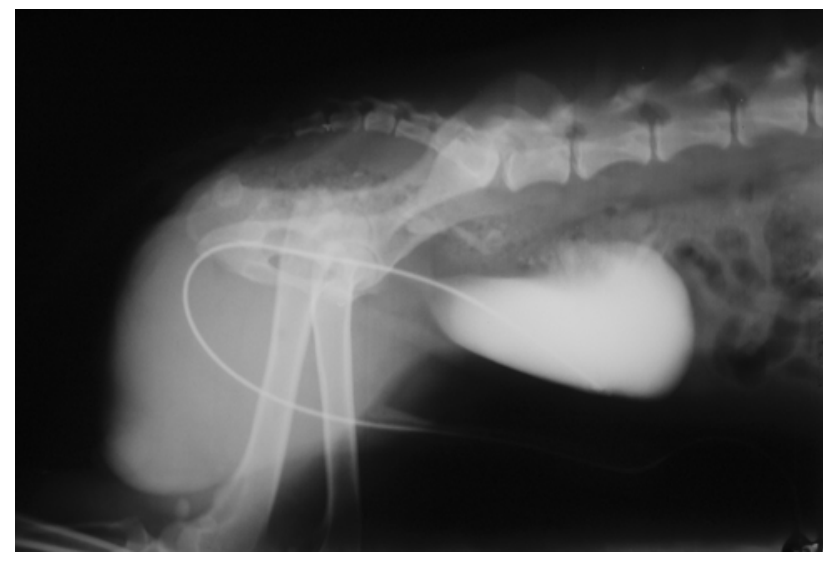

DISCUSSÃo

Diferentemente da hipospadia, onde a uretra se abre ventral e caudalmente ao orifício normal e há freqüentemente a presença de outras anormalidades congênitas (criptorquidismo, intersexualidade, anormalidades escrotais, pênis subdesenvolvido e anormal), as fístulas uretrais podem ocorrer isoladas, sem que esteja presente qualquer outra alteração no sistema genito-urinário [1,6], fato ocorrido neste caso, uma vez que o animal não apresenta qualquer alteração dos órgãos genitais.

Devido à variedade na aparência das fístulas congênitas, com ou sem hipospadia, a etiologia é provavelmente multifatorial e estas devem ser diferenciadas das duplicações uretrais. Para alguns, as fístulas uretrais, particularmente aquelas onde há uma fistula perineal, são classificadas como uma variante da duplicação uretral em Y $[1,3,9,10]$. No caso aqui relatado, o animal apresentava trajeto fistuloso na região perianal
Figura 6. Uretrocistografia de contraste positivo 15 dias após a cirurgia. Notar o trajeto completo da uretra (seta) (Liziane Ferraresi Holanda Cavalcante).

e através da uretrocistografia retrógrada observou-se a comunicação do mesmo com a bexiga. A presença de fístula uretral foi confirmada baseada no exame histopatológico, demonstrando a presença de tecido conjuntivo bem diferenciado e ausência de epitélio uretral, podendo-se excluir a suspeita de uretra dupla. Visto que não havia histórico de trauma, a fístula uretral pôde ser considerada de origem congênita.

Apesar das complicações pós-operatórias (deiscência de pontos), concluiu-se que o procedimento cirúrgico obteve sucesso na oclusão da fístula uretral e recuperação completa do animal.

\section{NOTAS INFORMATIVAS}

${ }^{1}$ Laboratório Intervet - Avenida Alfredo Egídio de Souza Aranha, 100 - Bloco B - $6^{\circ}$ andar - Vila Cruzeiro, São Paulo/ SP.

${ }^{2}$ Laboratório Schering do Brasil - Rua Cancioneiro de Évora, 255 - Santo Amaro, São Paulo/SP.

${ }^{3}$ Laboratório Pfizer - Rua Alexandre Dumas, 1860. Chácara Santo Antônio, São Paulo/SP.

\section{REFERÊNCIAS}

1 Caldamone A.A., Chen S., Elder J.S., Ritchey M.L., Dianond D.A. \& Koyle M.A. 1999. Congenital Anterior Urethrocutaneous Fistula. The Journal of Urology. 162: 1430-1432.

2 Edney M.T., Lopes J.F., Schned A., Ellsworth P. \& Cendron M. 2004. Time Course and Histological of Urethrocutaneous Fistula Formation in a Porcine Model of Urethral Healing. European Urology. 45: 806-810.

3 Haleblian G., Kraklau D., Wilcox D., Duffy P., Ransley P. \& Mushtaq I. 2006. Y-Type Urethral Duplication in the Male. British Journal of Urology. 97: 597-602.

4 Harjai M.M. 2000. Congenital Urethrocutaneous Fistula. Journal of Internal Pediatric Surgery. 16: 386-387.

5 Hedlund C.S. \& Hosgood G. 1996. Moléstia Uretral e Uropatia Obstrutiva. In: Bojrab M. J. (Ed.). Mecanismo da Moléstia Cirúrgica em Pequenos Animais. 2. ed. São Paulo: Manole, pp. 617-625.

6 Hedlund C.S. 2002. Cirurgia dos Sistemas Reprodutivo e Genital. In: Fossum T. W. (Ed.). Cirurgia de Pequenos Animais. São Paulo: Roca, pp. 571-637.

7 Lal P., Gupta A., Krishna A. \& Taneja K. 1998. Congenital H-Hype Urethroanal Fistula. Journal of Internal Pediatric Surgery. 13: 193-194. 
8 Nakane A., Hayashi Y., Kojima Y., Mizuno k., Okada A., Sasaki S. \& Kohri K. 2000. Congenital Urethrocutaneous Fistula. International Journal of Urology. 7: 343-344.

9 Sánchez M.M., Vellibre R.M., Castelo J.L.V., Arias M.P., Sarmiento R.C. \& Costa A.R. 2006. A New case of Male Y-type Urethral Duplication and Review of Literature. Journal of Pediatric Surgery. 41: E69-E71.

10 Savanelli A., Schiano A., Esposito C., Russo S. \& Dolezalova H. 1998. Congenital Megalourethra Associated with duplication and Imperforate Anus. Journal of Internal Pediatric Surgery. 13: 607-609.

11 Schwartz A., Lipowitz A.J. \& Burt J. 1974. Urinary Incontinence due to Multiple Urogenital Anomalies in mature Dog. Journal of American Veterinary Medical Association. 164: 1021-1024. 